\title{
Effectivity of anti-oxidative enzymatic system on diminishing the oxidative stress induced by aluminium in chickpea (Cicer arietinum L.) seedlings
}

\section{Sushant Singh ${ }^{1}$, Anil Verma ${ }^{2}$, Vikash Kumar Dubey ${ }^{3 *}$}

\author{
${ }^{1}$ Centre for Environment, Indian Institute of Technology Guwahati, Assam, India. \\ ${ }^{2}$ Centre for Environment, Indian Institute of Technology Guwahati, Assam, India; Department of Chemical \\ Engineering, Indian Institute of Technology Guwahati, Assam, India.
}

${ }^{3}$ Centre for Environment, Indian Institute of Technology Guwahati, Assam, India; Department of Biotechnology, Indian Institute of Technology Guwahati, Assam, India.

*Corresponding author: vdubey@iitg.ernet.in

Received: 23 July, 2011; Accepted: 26 June, 2012

\begin{abstract}
We explore physiological and biochemical response under increasing aluminium stress at different time interval in chickpea seedlings (Cicerarietinum L.). Germination percentage and root length were found to be highly reduced under increasing metal stress. Aluminium induced oxidative stress and led to fluctuations in antioxidative activity responses. Roots showed higher antioxidative activity compared to shoots. Low concentration of aluminium after a brief treatment induced higher superoxide dismutase (SOD; EC 1.15.1.1), ascorbate peroxidase (APX; EC 1.11.1.11) and guaiacol peroxidase (GPX; EC 1.11.1.7) activity whereas longer duration of treatment led to decrease in these activities. Malondialdehyde concentration indicated higher oxidative damage in roots compared to shoots. Taken together the data obtained indicated that high concentration and long exposition of aluminium increases oxidative stress and impairs antioxidative defense system, overall leading to poor growth and survival of seedlings.
\end{abstract}

Keywords: ascorbate peroxidases, heavy metal, malondialdehyde, superoxide dismutase, oxidative stress.

\section{INTRODUCTION}

Various anthropogenic activities are responsible for heavy metal toxicity to agricultural land. Data show 235 million hectares of land being polluted by toxic heavy metals (Giordani et al., 2005). Aluminium is one of the primary toxic metals found as $\mathrm{Al}^{+3}$ ions, its toxic form, in acid soils. Almost $50 \%$ of the agricultural lands are acidic in nature thus making $\mathrm{Al}^{+3}$ a commonly toxic metal pollutant worldwide (Kochian et al., 1995).

Oxidative stress is due to increased production of reactive oxygen species (ROS), which hinders the normal functioning of metabolic process and damages cell membrane, proteins, DNA and chloroplast (Fang and Kao, 2000). The different ROS include superoxide anion $\left(\mathrm{O}_{2}^{-}\right)$, hydroxyl radicals $\left(\mathrm{OH}^{-}\right)$, singlet oxygen $\left(10_{2}\right)$ and hydrogen peroxide $\left(\mathrm{H}_{2} \mathrm{O}_{2}\right)$. The increased concentration of ROS is partly balanced by antioxidative defense systems, which include enzymes such as superoxide dismutase (SOD; EC 1.15.1.1), ascorbate peroxidase (APX; EC 1.11.1.11) and guaiacol peroxidase (GPX; EC 1.11.1.7). These enzymes scavenge generated free radicals to maintain oxidative balance in the cell. ROS formation is unavoidable in aerobic organism even under normal metabolic condition, however its concentration 
remains low. Under toxic metal stress condition, the formation of ROS is enhanced and the defense system is required to balance its level mostly due to a higher induction of antioxidative enzymes (Taylor et al., 2009). SOD works over $\mathrm{O}_{2}$-radicals and leads to formation of $\mathrm{H}_{2} \mathrm{O}_{2}$ and $\mathrm{O}_{2}$ and different peroxidases such as APX and GPX scavenge $\mathrm{H}_{2} \mathrm{O}_{2}$ (Zhang et al., 2007). Increased level of ROS is also responsible for lipid peroxidation on cell membrane and the malondialdehyde (MDA), a cytotoxic product of lipid peroxidation, is used as an indicator of membrane damage (Reddy et al., 2005).

Studies focusing aluminium toxicity and antioxidative defense as influenced by oxidative stress has been carried out in several crops as Pisum sativum (Yamamoto et al., 2001), Triticum aestivum (Snowden et al., 1993), Glycine max (Cakmak and Horst, 1991) and Cicer arietinum L., an important legume crop with high protein content (Sahu et al., 2010). It has been reported that chickpea possess tolerance ability for aluminium (Singh and Raje, 2011). In this paper we aimed to report effect of aluminium stress in germinating chickpea seedlings under various concentrations. Physiological parameters such as percentage germination, root/shoot length and biochemical analysis in terms of antioxidative enzymes response had been performed at different time interval respectively.

\section{MATERIAL AND METHODS}

Plant material, germination condition and aluminium treatment: Chickpea seeds (Cicer arietinum L.) obtained from certified sources was used for experiment. After imbibition for overnight seeds were germinated in glass container (100 mm diameter) containing Hoagland's nutrient solution ( $\mathrm{pH} 5.0)$ with varying concentration of $\mathrm{Al}^{+3}$ (i.e.; 25, 100, 200, 400, 1,000, 2,000 and 3,000 $\mu \mathrm{M}$ ). A separate control plate was also maintained with nutrient solution only. Aluminium was provided in the form of $\mathrm{Al}_{2} \mathrm{SO}_{4} \cdot 6 \mathrm{H}_{2} \mathrm{O}$. Germination was done in dark for initial 2 days after that regular exposure of light: dark condition was provided and analyzed after $8^{\text {th }}, 15^{\text {th }}$ and $21^{\text {st }}$ day of germination for root length, shoot length, antioxidative enzymes and lipid peroxidation. The control and experimental seeds were germinated in Hoagland's nutrient by keeping other parameters constant $(\mathrm{pH}$, temperature, humidity etc.). The only variable was aluminium concentration.

Germination was evaluated on $8^{\text {th }}$ day after initial seed plating. Seeds were considered to be germinated when both plumule and radicle were extended from their junctions. Subsequent measurement for root and shoot length was taken on $8^{\text {th }}, 15^{\text {th }}$ and $21^{\text {st }}$ day of germination taking 3 random readings from each sample.

Enzyme extraction and antioxidative assays: Enzyme extraction was carried out at $4^{\circ} \mathrm{C}$. Samples $(0.25 \mathrm{~g})$ taken from root and shoot of $\mathrm{Al}^{+3}$ treated plant was homogenized separately in $3 \mathrm{~mL}$ phosphate buffer ( $100 \mathrm{mM}, \mathrm{pH} 7.8$ ) containing $1 \mathrm{mM}$ disodium-EDTA in a prechilled mortar and pestle. The homogenate was centrifuged at $10,000 g_{n}$ for 20 minutes at $4^{\circ} \mathrm{C}$ and supernatant collected for SOD, APX, GPX and lipid peroxidation assay.

SOD assay was performed by riboflavin mediated NBT reduction method of Gunes et al. (2009). Reaction volume (3 $\mathrm{mL}$ ), containing $13 \mathrm{mM}$ methionine, $75 \mu \mathrm{M}$ NBT, $0.1 \mathrm{mM}$ EDTA and $4 \mu \mathrm{M}$ riboflavin in $50 \mathrm{mM}$ phosphate buffer ( $\mathrm{pH}$ 7.8) in glass test tubes, was placed under fluorescent light $(13 \mathrm{~W})$ in foil lined box for 10 minutes and then spectroscopic measurement was performed at $560 \mathrm{~nm}$. Blank (without illumination) and control (without enzyme) was also prepared. One unit of SOD was defined as the amount of enzyme producing $50 \%$ inhibition of NBT reduction under assay condition.

APX activity was determined as described earlier by Gracía-Limones et al., (2002) with minor modification. In brief, reaction mixture of $1 \mathrm{~mL}$ consisted of $100 \mu \mathrm{L}$ ascorbate solution $(5 \mathrm{mM}), 100 \mu \mathrm{H}_{2} \mathrm{O}_{2}(100 \mathrm{mM})$, $100 \mu \mathrm{L}$ EDTA solution ( $1 \mathrm{mM}$ ) and $100 \mu \mathrm{L}$ of plant extract in $600 \mu \mathrm{L}$ of phosphate buffer $(100 \mathrm{mM}, \mathrm{pH}$ 7.0). The oxidation of ascorbate was measured with decrease in absorbance at $290 \mathrm{~nm}$ for 3 minutes and activity calculated with help of extinction coefficient $\left(2.8 \mathrm{mM}^{-1} \mathrm{~cm}^{-1}\right)$.

GPX assay was performed using earlier described method by Roy et al., (1996). Reaction mixture of $1 \mathrm{~mL}$ consisted of $100 \mu \mathrm{L}$ guaiacol (34 mM), $100 \mu \mathrm{L} \mathrm{H}_{2} \mathrm{O}_{2}$ $(100 \mathrm{mM}), \quad 100 \mu \mathrm{L}$ plant extract in phosphate buffer (100 mM, pH 7.0). Oxidation of guaiacol was measured by increase in absorbance at $470 \mathrm{~nm}$ for 3 minutes and activity calculated with the help of extinction coefficient $\left(26.6 \mathrm{mM}^{-1} \mathrm{~cm}^{-1}\right)$.

Lipid peroxidation was determined by the thiobarbituric acid (TBA)-trichloro acetic acid (TCA) method of Dazy et al. (2009). MDA on reacting with TBA forms MDA-TBA complex known as TBA reactive substances (TBARS) which has specific absorbance at $532 \mathrm{~nm}$ and non-specific absorbance at $600 \mathrm{~nm}$. MDA concentration was determined with the help of extinction coefficient $\left(155 \mathrm{mM}^{-1} \mathrm{~cm}^{-1}\right)$. Protein content 
determination in all the above enzymatic preparation was done by Bradford method (1976) taking bovine serum albumin (BSA) as standard as followed in our earlier publication Singh et al. (2010).

\section{RESULTS AND DISCUSSION}

Abiotic stress in terms of metal toxicity remains unavoidable for germinating plants with changing environmental condition in which toxicity in agricultural land is increasing. Among various toxic metals, aluminium is the most common pollutant and found in acidic soils in toxic $\mathrm{Al}^{+3}$ ionic forms. Effects of aluminium on few plants have been previously studied by Delhaize and Ryan (1995) indicating towards its toxicity in germinating plants. Aluminium toxicity stress in chickpea had been previously reported by Sahu et al. (2010). However, the metal concentration and germination condition differs from the present study. Altogether these reports indicate the existence of antioxidative response variations due to aluminium toxicity in germinating chickpea seedlings. In the present work, toxic effects of aluminium were verified by the inhibition in seedlings germination and root/shoot length (Figures 1 and 2). Similar effects had also been reported for rice and wheat varieties with increasing metal concentration by Shri et al. (2009) and Liu et al. (2005), respectively. Rooting was also affected by increased aluminium concentrations (Figure 2A). Root development was inhibited on 2,000 and 3,000 $\mu \mathrm{M}$. Interestingly, shooting was affected at much higher concentration (Figure $2 \mathrm{~B}$ ) and it has been hypothesized that under heavy metal stress the inhibition

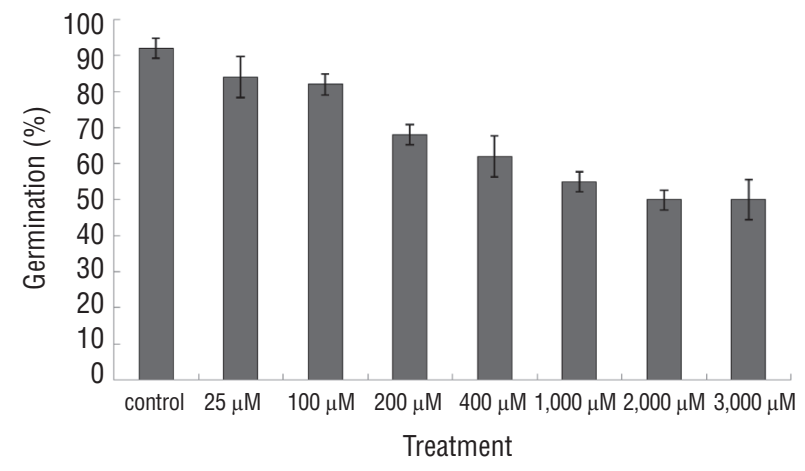

Figure 1. Germination (\%) of chickpea seeds under metal stress. Germination was considered when plumule and radicle grown over $10 \mathrm{~mm}$ long and counted on $8^{\text {th }}$ day after treatment. Results are mean value of multiple experiments and plotted in form of seed response \pm standard deviation.

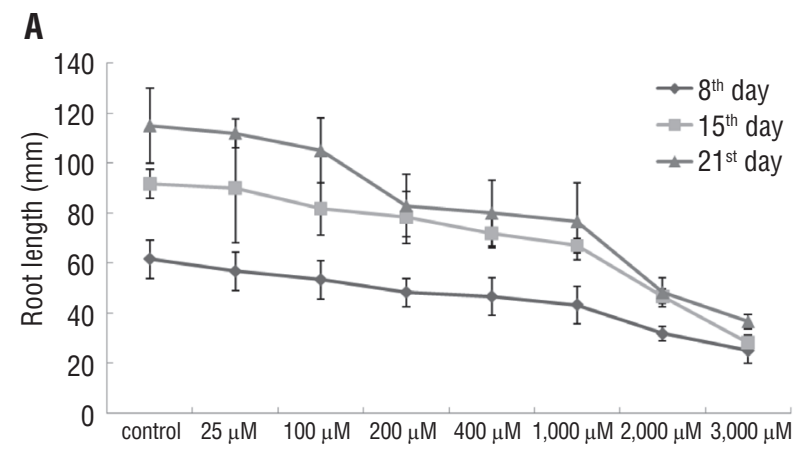

Treatment

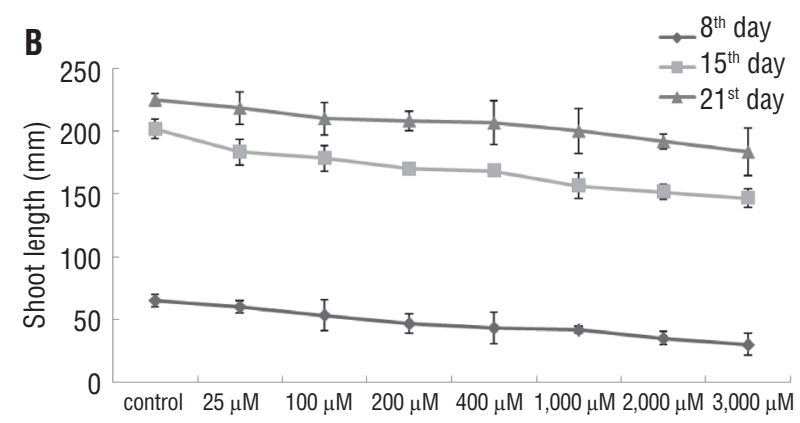

Treatment

Figure 2. Graph showing (A) root and (B) shoot length of $\mathrm{Al}^{+3}$ treated chickpea seeds. Data obtained on $8^{\text {th }}, 15^{\text {th }}$ and $21^{\text {st }}$ day are the mean value of 3 randomly selected sample and plotted in form of root length \pm standard deviation.

of cell division on shoots takes place (Pan et al., 2001). Rooting gets inhibited due to direct contact with metals in nutrient media, interfering with normal cellular division and growth pattern.

Toxic metal concentration intensify oxidative stress condition which gets counteracted by an efficient antioxidative defense system consisting of ROS scavenging enzymes (Liu et al., 2007). SOD is the primary enzyme acting as a first line of defense involved with the dismutation of superoxide radicals $\left(\mathrm{O}_{2}^{-}\right)$into $\mathrm{H}_{2} \mathrm{O}_{2}$ and $\mathrm{O}_{2}$. SOD response was collected on $8^{\text {th }}, 15^{\text {th }}$ and $21^{\text {st }}$ day of germination for root and shoot. Increased SOD activity was observed at lower aluminium concentration of 25 , 100 and $200 \mu \mathrm{M}$ (Figure 3). The initial increase in SOD activity was consistent with reports on maize and barley, in which heavy metal stress leads to increase in SOD activity with respect to control (Boscolo et al., 2003; Guo 
et al., 2004). However beyond $100 \mu \mathrm{M}$, a decrease in SOD activity in chickpea seedlings was observed in roots and shoots over a long exposure.

As SOD activity was decreased with various aluminium concentrations over a long time, it might be due to high concentration of $\mathrm{H}_{2} \mathrm{O}_{2}$ produced via an unknown pathway affecting SOD induction. Arsenic has been observed to decrease SOD activity while maintaining POD activities (Gunes et al., 2009), what might indicate that high levels of $\mathrm{H}_{2} \mathrm{O}_{2}$ were produced by another pathway. Similar conclusions on SOD activities getting impaired at higher
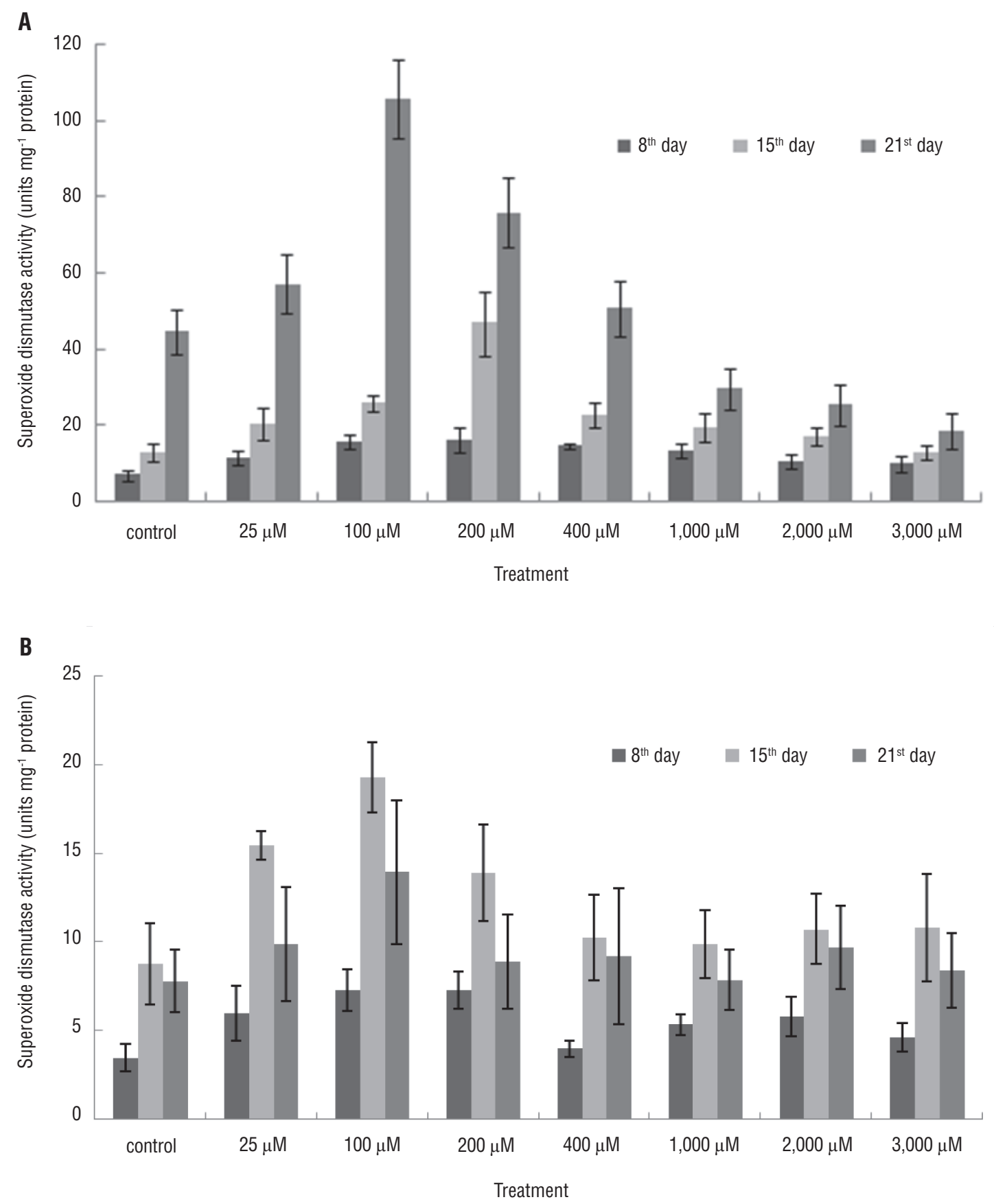

Figure 3. Superoxide dismutase activities of $(A)$ root and (B) shoot samples of chickpea seeds germinated under $A l^{+3}$ stress. Assay performed by the NBT reduction method. Results obtained are mean value of multiple experiments \pm standard deviation. 
aluminium concentration, as much as $3.5 \mathrm{mM}$ had also been reported previously by Sahu et al. (2010). The initial high activity of SOD leads to accumulation of $\mathrm{H}_{2} \mathrm{O}_{2}$ and as a result, higher $\mathrm{H}_{2} \mathrm{O}_{2}$ concentration induces different peroxidases such as APX and GPX to balance its level (OImos et al., 2003). APX activity was found to be increased under aluminium stress in both root and shoot (Figures $4 \mathrm{~A}$ and $B$ ) initially, with high activity in root. In case of shoots, APX activity gets saturated later which is in accordance to decrease in SOD activity. The APX activity in roots showed increase from $8^{\text {th }}$ day to $21^{\text {st }}$ day while gradually decreasing at high aluminium concentration i.e. above 200
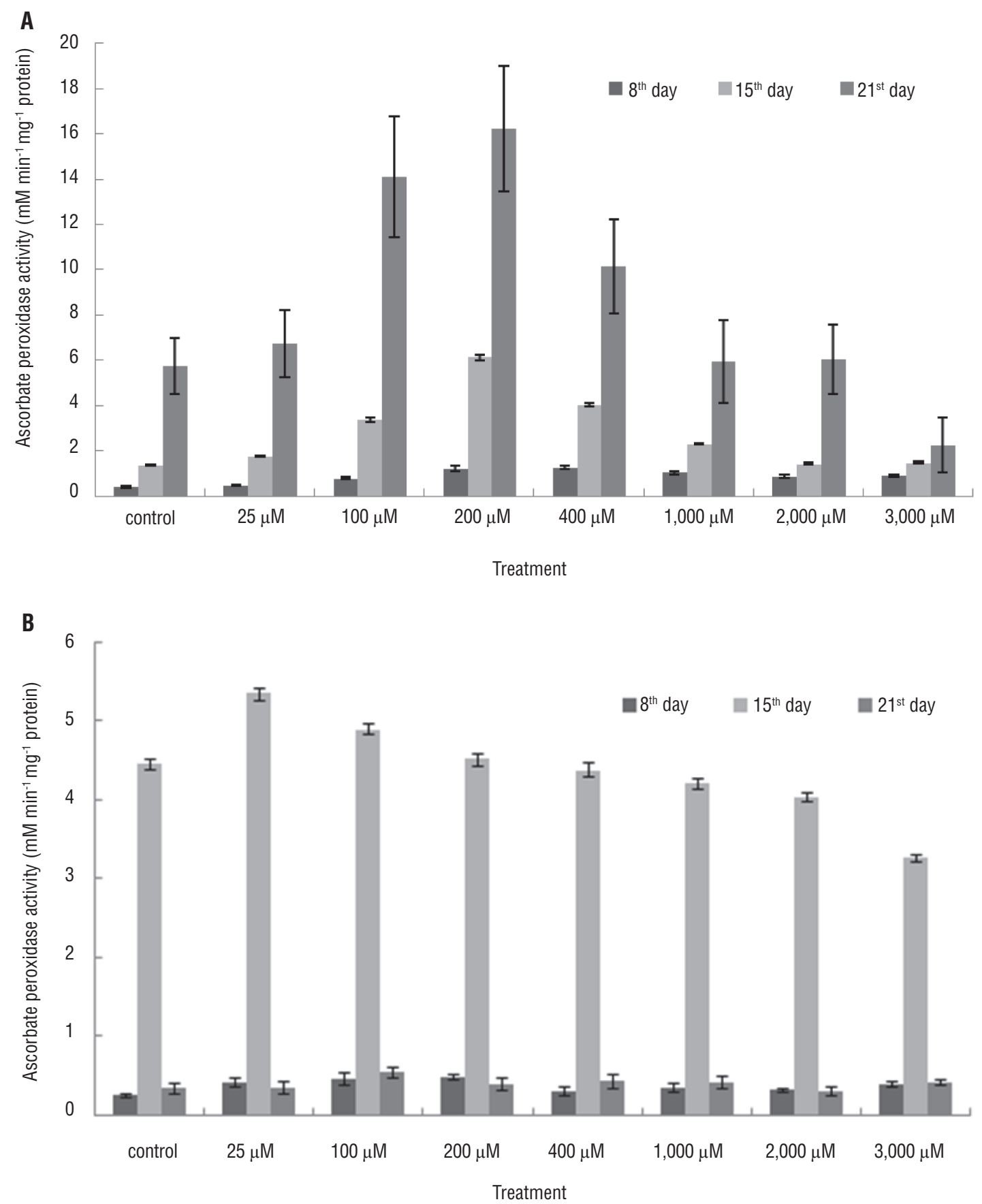

Figure 4. Ascorbate peroxidase activities of $(A)$ root and (B) shoot samples of $\mathrm{Al}^{+3}$ treated chickpea seeds. Assay performed include oxidation of ascorbate, a substrate for APX enzyme activity. Results are presented as mean value of multiple experiments \pm standard deviation. 
$\mu \mathrm{M}$. High APX activity in root was in consistence with the reports of Schutzendubel et al. (2001) and its pattern was similar to SOD activity in roots.

GPX is another antioxidative enzyme which hydrolyzes $\mathrm{H}_{2} \mathrm{O}_{2}$ and depletes oxidative load generated. In case of root
(Figure 5A), an increase in GPX activity has been observed with increasing aluminium concentrations and in a similar manner to other antioxidative enzymes, however at higher metal concentration it gets saturated. The $21^{\text {st }}$ day response reveals saturated GPX activity in all treatments under metal stress which is due to high oxidative load and thus leading to

A

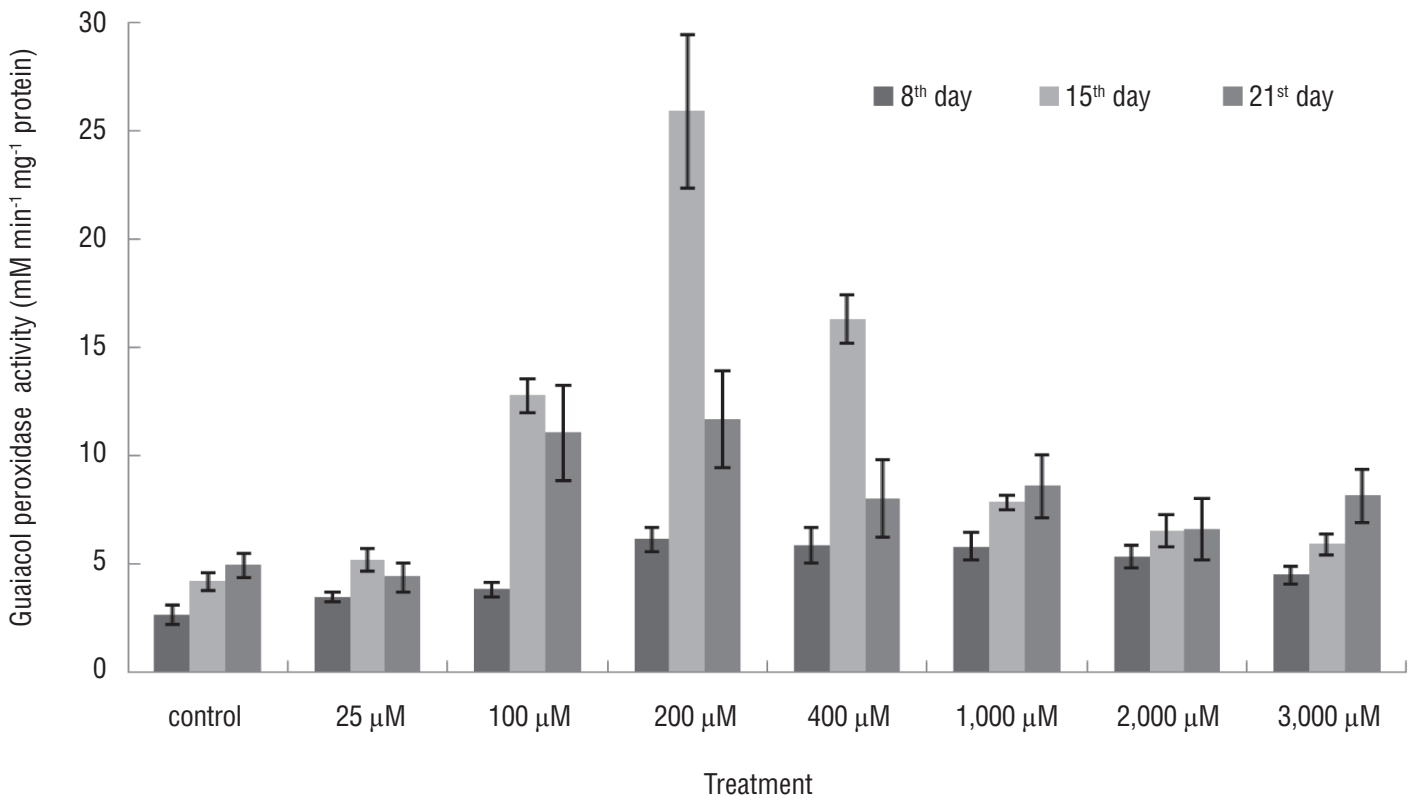

B

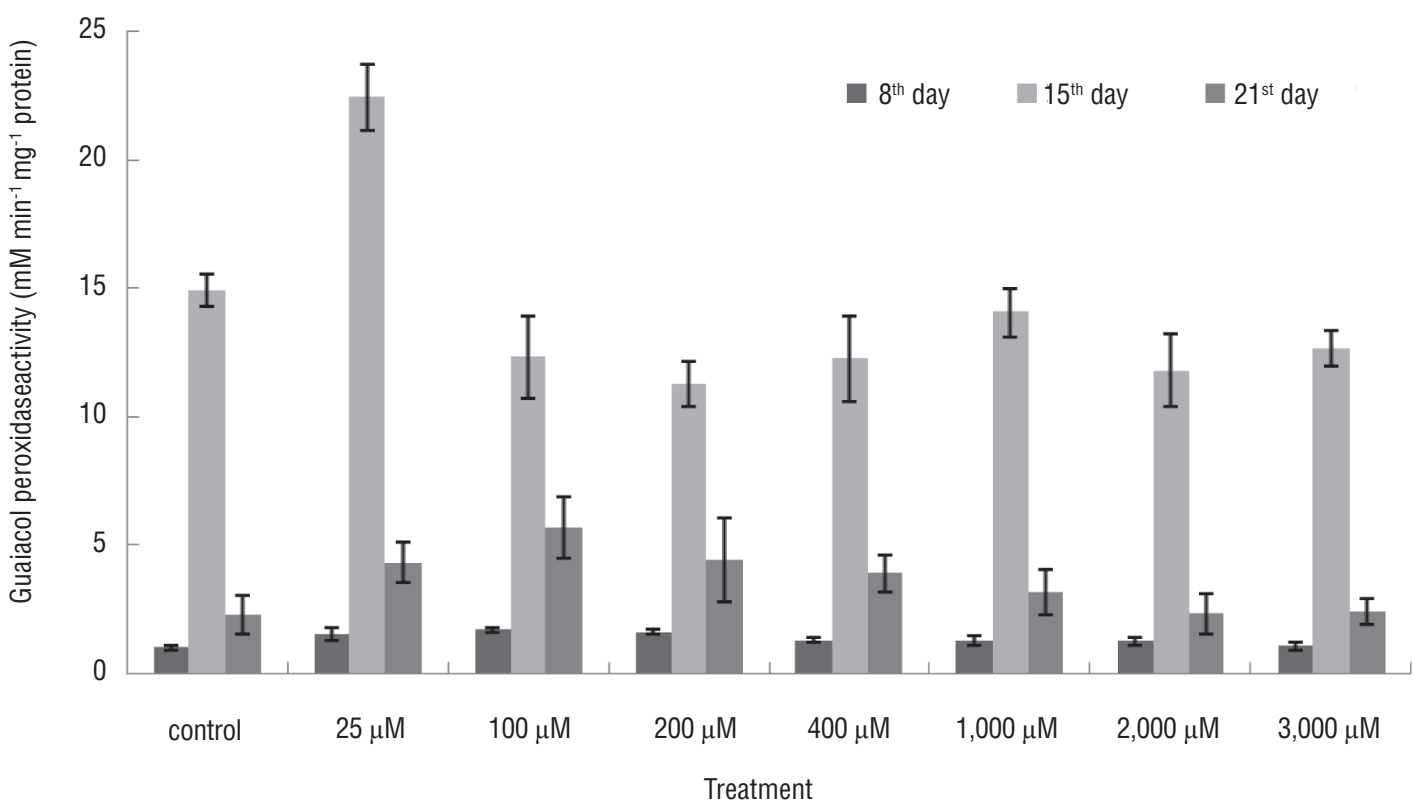

Figure 5. Guaiacol peroxidase activities of (A) root and (B) shoot samples under $\mathrm{Al}^{+3}$ stress in chickpea seeds. Results are presented as mean value of multiple experiments \pm standard deviation. 
its inhibition. The duration of treatment with increasing metal concentration induced high oxidative load onto germinating plant, leading to saturation of antioxidative enzymes.

Lipid peroxidation estimates membrane damage under oxidative stress and MDA, a product of lipid peroxidation, is used as indicator for oxidative damage. Result indicates increase in MDA concentration with increasing aluminium treatment both in roots as well as in shoots (Figures $6 \mathrm{~A}$ and $B$ ). MDA concentration was found to be higher in root which indicates high peroxidation effect due to direct contact with heavy metals and thus the overall increase in MDA content indicates oxidative damage. Increase in antioxidative activity of SOD, APX and GPX saturates

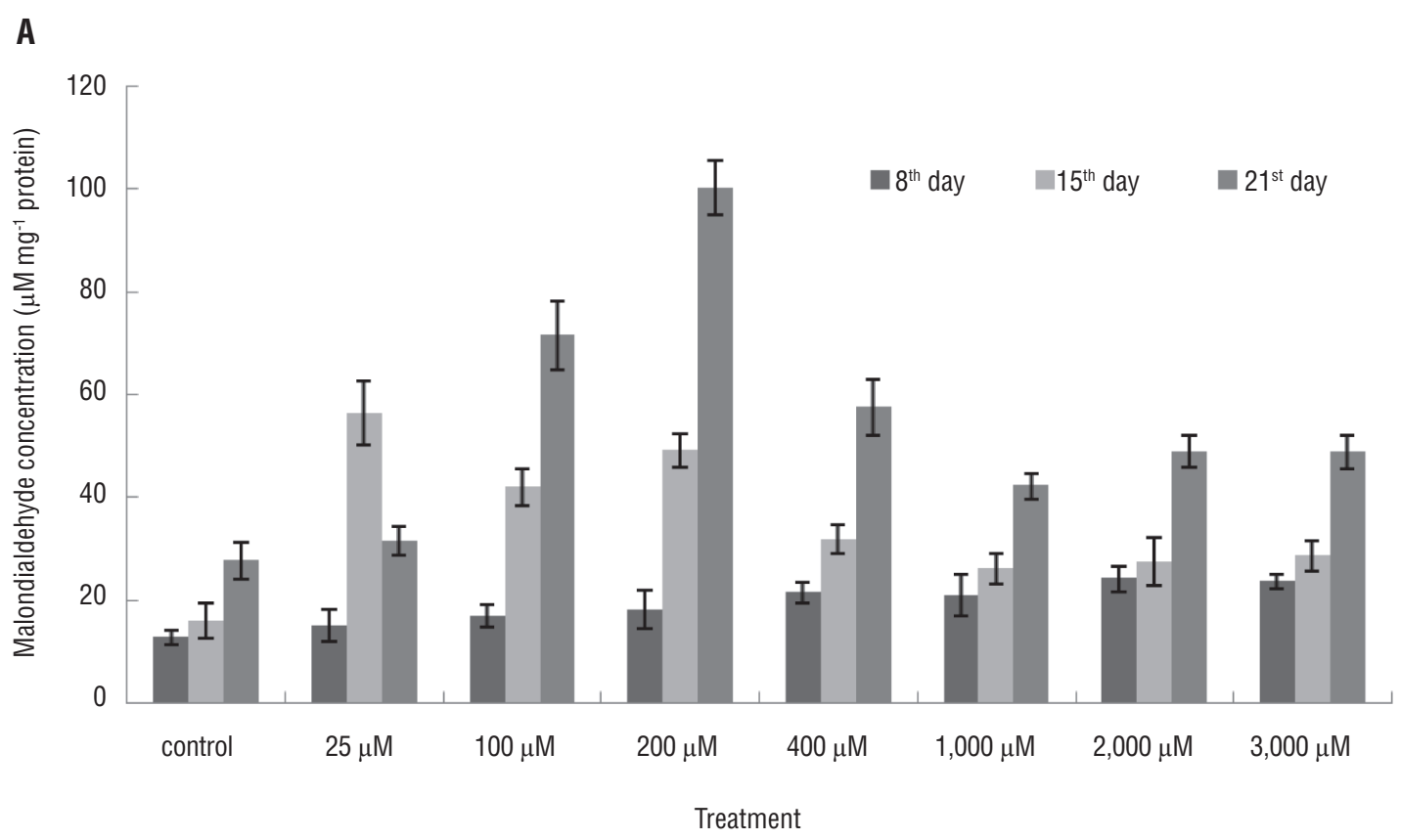

B

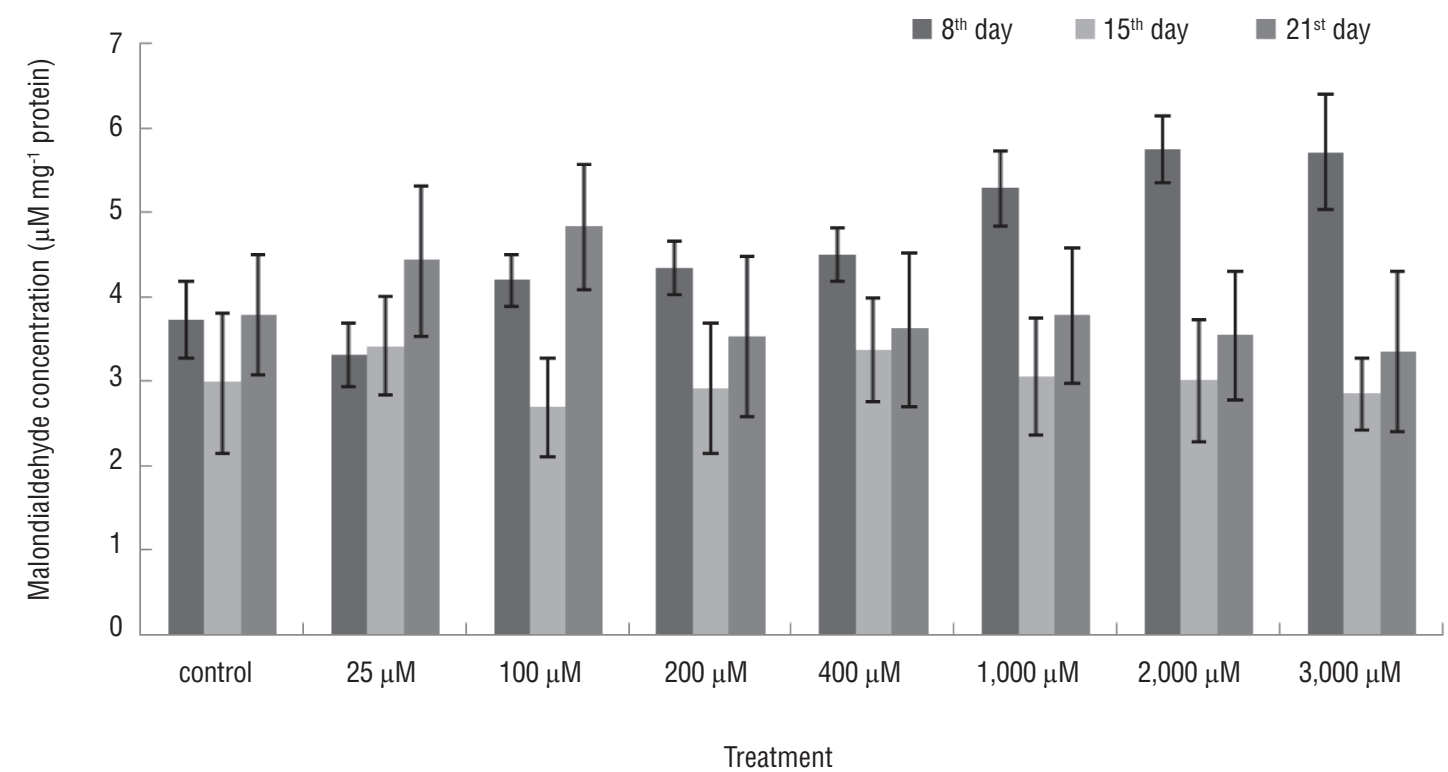

Figure 6. Graph showing malondialdehyde concentration (A) root sample and (B) shoot sample of $\mathrm{Al}^{+3}$ metal treated chickpea seeds. MDA results from the peroxidation effect of TBA and TCA. Results obtained are mean value of multiple experiments \pm standard deviation. 
when damage to lipid peroxidation is high, as observed in case of $15^{\text {th }}$ day data. Similar response under heavy metal stress has been reported in mangrove plant seedlings (Zhang et al., 2007).

In conclusion, the report presents an overview of antioxidative response under increasing aluminium stress in germinating chickpea seeds indicating that low concentration induced antioxidative defense efficiently. However, long exposition and higher concentration deregulates its antioxidative defense system. A relation observed between SOD and peroxidases, APX and GPX indicates synchronous fluctuation of its antioxidative activities.

Acknowledgments: PhD fellowship to SS was granted by Indian Institute of Technology Guwahati. Infrastructure facilities by IIT Guwahati and Financial support by DST in form of research grant (F. No. SR/S0/PS/40/2010) are with kind regards, acknowledged.

\section{REFERENCES}

Boscolo SRP, Menossib M, Jorgea AR (2003) Aluminum-induced oxidative stress in maize. Phytochem. 62:181-189.

Bradford MM (1976) A rapid and sensitive method for the quantification of microgram quantities of protein utilizing the principle of protein-dye binding. Analyt. Biochem. 72:248-254.

Cakmak I, Horst WJ (1991) Effect of aluminum on lipid peroxidation, superoxide dismutase, catalase, and peroxidase activities in root tips of soybean (Glycine max). Physiol. Plantarum. 83:463-468.

Dazy M, Masfaraud FJ, Férard FJ (2009) Induction of oxidative stress biomarkers associated with heavy metal stress in Fontinalis antipyretica Hedw. Chemosphere 75:297-302.

Delhaize E, Ryan PR (1995) Aluminium toxicity and tolerance in plants. Plant Physiol. 107:315-327.

Fang W, Kao H (2000) Enhanced peroxidase activity in rice leaves in response to excess iron, copper and zinc. Plant Sci. 158: 71-76

García-Limones C, Hervas A, Navas-Cortés AJ, Jiménez-Diaz MR, Tena $M(2002)$ Induction of an antioxidant enzyme system and other oxidative stress markers associated with compatible and incompatible interactions between chickpea (Cicer arietinum L.) and Fusarium oxysporum f. sp. Ciceris. Physiol. Mol. Plant Pathol. 61:325-337.

Giordani C, Cecchi S, Zanchi C (2005) Phytoremediation of soil polluted by nickel using agricultural crops. Environ. Manag. 36:675-681.

Gunes A, Pilbeam JD, Inal A (2009) Effect of arsenic-phosphorus interaction on arsenic-induced oxidative stress in chickpea plants. Plant Soil 314:211-220.
Guo TR, Zhang GP, Zhou MX, Wu FB, Chen JX (2004) Effect of aluminium and cadmium toxicity on growth and antioxidant enzyme activities of two barley genotypes with difference Al tolerance. Plant Soil 258:241-248.

Kochian VL (1995) Cellular mechanisms of aluminum toxicity and resistance in plants. Annu. Rev. Plant Physiol. and Plant Mol Biol. 46:237-260.

Liu X, Zhang S, Shan X, Christie P (2007) Combined toxicity of cadmium and arsenate to wheat seedlings and plant uptake and antioxidative enzyme responses to cadmium and arsenate co-contamination. Ecotoxicol. Environ. Saf. 68:305-313.

Liu X, Zhang S, Shan S, Zhu ZG (2005) Toxicity of arsenate and arsenite on germination, seedling growth and amylolytic activity of wheat. Chemosphere 61:293-301.

Olmos E, Martínez-Solano RJ, Piqueras A, Hellín E (2003) Early step in the oxidative burst induced by cadmium in cultured tobacco cells (BY-2 line). J. Exp. Bot. 54:291-301.

Pan WJ, Zhu YM, Chen $\mathrm{H}$ (2001) Aluminum-induced cell death in root-tip cells of barley. Environmental Exp. Bot. 46: 71-79.

Reddy MA, Kumar GS, Jyothsnakumari G, Thimmanaik S, Sudhakat C (2005) Lead induced changes in antioxidant metabolism of horsegram (Macrotyloma uniflorum (Lam) Verdc.) and bengalgram (Cicer arietinum L.). Chemosphere 60:97-104.

Roy S, Sen KC, Hanninen 0 (1996). Monitoring polycyclic aromatic hydrocarbons using 'moss bags': bioaccumulation and responses of antioxidant enzymes in Fontinalis antipyretica Hedw. Chemosphere. 32:2305-2315.

Sahu KK, Biswas D, Naithani SC (2010) Aluminium stress on germinating seeds of Cicer arietinum. Edition No. 1 VDM Publishing House, Sep, pp. 96

Schutzendubel A, Schwanz P, Teichmann T, Gross K, Langenfeld-Heyser R, Godbold LD, et al. (2001) Cadmium-induced changes in antioxidative systems, hydrogen peroxide content, and differentiation in scots pine roots. Plant Physiol. 127:887-898.

Shri M, Kumar S, Chakrabarty D, Trivedi PK, Mallick S, Mishra P et al. (2009) Effect of arsenic on growth, oxidative stress, and antioxidant system in rice seedlings. Ecotoxicol. Environ. Saf. 72:1102-1110.

Singh AN, Shukla AK, Jagannadham MV, Dubey VK (2010). Purification of a novel cysteine protease, procerain $B$, from Calotropis procera with distinct characteristics compared to procerain. Process Biochemistry. 45:399-406.

Singh D, Raje RS (2001) Genetics of aluminium tolerance in chickpea (Cicer arietinum ). Plant Breeding 130:5, 563-568.

Snowden CK, Gardner CR (1993). Five genes induced by aluminium in wheat (Triticum aestivum L.) roots. Plant Physiol. 103:855-861.

Taylor, LN, Tan Y, Jacoby RP, Millar AH (2009) Abiotic environmental stress induced changes in the Arabidopsis thaliana chloroplast, mitochondria and peroxisome proteomes. J. Proteomics 72:367-378.

Yamamoto Y, Kobayashi Y, Matsumoto H (2001) Lipid peroxidation is an early symptom triggered by aluminum, but not the primary cause of elongation inhibition in pea roots. Plant Physiol. 125:199-208.

Zhang QF, Wang SY, Lou PZ, Dong DJ (2007) Effect of heavy metal stress on antioxidative enzymes and lipid peroxidation in leaves and roots of two mangrove plant seedlings (Kandelia candel and Bruguiera gymnorrhiza). Chemosphere 67:44-50. 